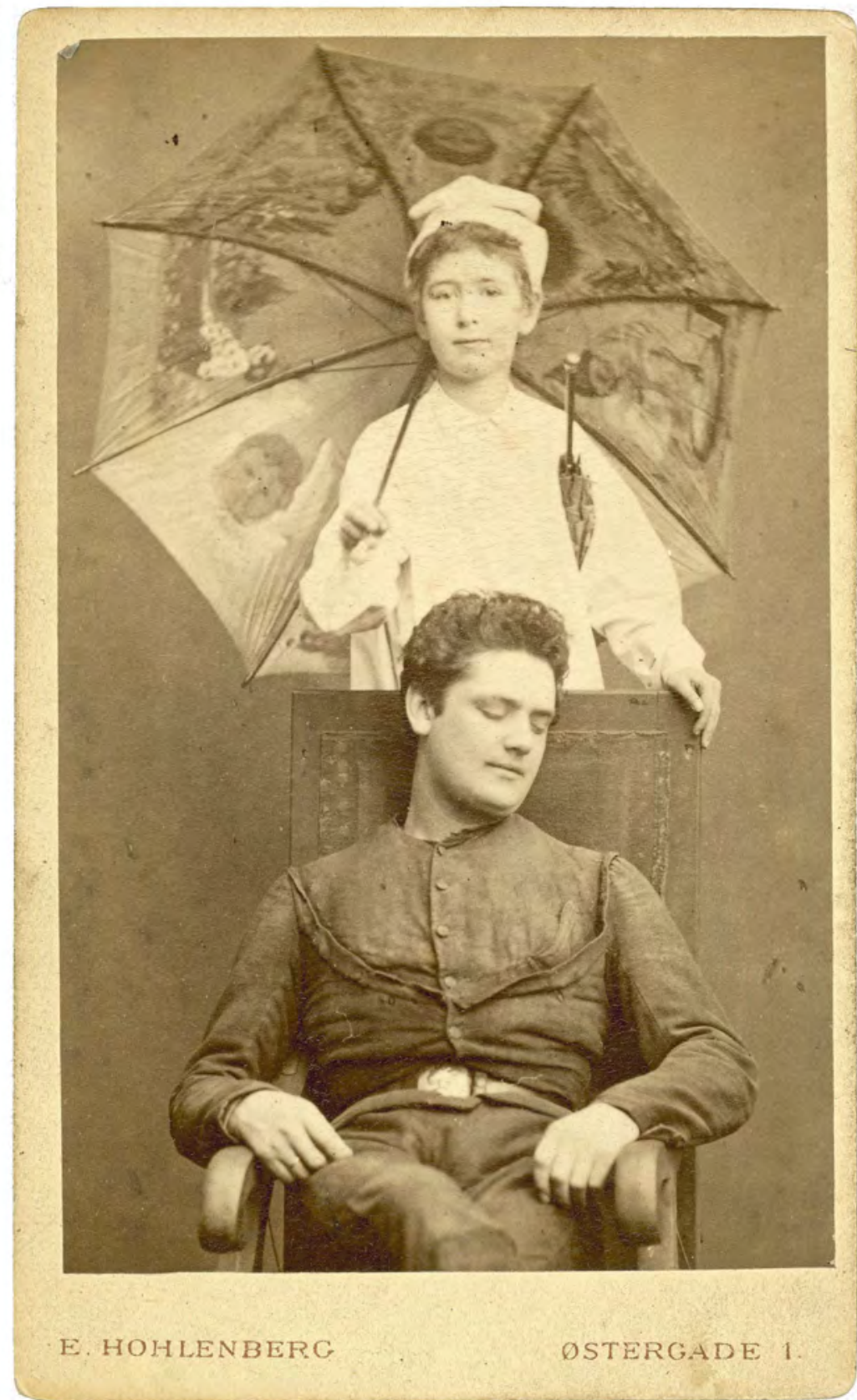

Christian Zangenberg som Christian of Olga Wiberg som Ole Lukøje i H.C. Andersens eventyrkomedie af samme navn (Casino Teatret, 1880). 
Tale ved åbningen 15. marts 2005

af udstillingen

\section{Digterens Teaterdrømme - H.C. Andersen og Teatret}

Af seniorforsker, dr.phil. Knud Arne Jürgensen

$\mathrm{D}$ eres Kongelige Højhed ! - Mine Damer og Herrer!

H.C. Andersen året er som bekendt vel begyndt - og må man sige - i fulde omdrejninger.

Det kan blandt andet ses af dagspressen, hvor udvalgte citater af eventyr-og teaterdigteren dagligt bringes på kultursiderne. Det skal nu ikke fraholde mig for ved denne lejlighed selv at indlede med to bemærkelsesværdige citater af vor store nationaldigter - citater som fortæller noget essentielt om de teater-gener, der var så stor en del af Andersens personlighed og er i fokus for den udstilling Det Kongelige Bibliotek i dag præsenterer officielt.

Det første citat stammer tilbage fra Andersens barndom - nærmere bestemt fra hans 13. år. Andersens elskede at optræde, fortælle og recitere - et karaktertræk, som hurtigt skaffede ham tilnavnet: "Der kleine Declamator".

\section{Odense skrev han omkring} 1818 i faderens aflagte regnskabsbog en såkaldt "Aria”, som han utvivlsomt har optrådt med ved flere lejligheder, og som fortæller noget væsentligt om hans stærke teaterdrift. Man kan sige, at han her på næsten profetisk vis antyder, hvordan teatret skulle få en stor plads i hans kunstnerliv. Denne tidlige "Aria" lyder som følger:
Ja jeg kan synge gjøre Tremulanter

Ja jeg kan spille som en Musikanter Jeg synge Ut re mi fa Sol

Jeg modulere i dur og mol

Jeg som Æsel vel kan skrige

I egnen findes ej min Lige

Jeg synge kan

Gik det ej an

Så hør en Gang

Min skjønne Sang

Jeg synger Bas Discant Tenor

Ja en Virtuos til Mand du får

Det var den 13-årige rapperdreng i Odense, Hans Christian, der her talte.

Præcis 30 år senere træder den nu 43-årige teaterdigter igen ind på scenen - men nu som den store - og officielle-deklamator i forbindelse med 100-års festen for Det Kongelige Teaters grundlæggelse. Det skete ved opførelsen af Andersens forspil "Kunstens Dannevirke", hvor digteren gennem skuespilleren Michael Wiehes foredrag fik fremført følgende meget sigende vers om teatrets og dets væsen:

Og allerlykkeligst er dog den Digter

Som tale kan fra Scenens Talerstol

Det er ei til en enkelt

Men til Mængden

Det hele Sollys gaaer!

Disse to citater omfavner på sin vis udstillingen Digterens TeaterdrømmeH.C. Andersen og Teatret, idet Andersen her selv klart hævder, at han både var draget og drevet frem af en indre livslang drift mod teatret og scenens kunst.

Af de i alt 34 sceniske arbejder han fik opført på Det Kongelige Teater og Casino-teatret i Amaliegade blev en tredjedel solide succeser og fik store opførelsestal, 
mens kun tre værker kan betegnes som deciderede fiaskoer.

I de mange Andersen biografier, litteraturhistorier og i forskningen står der ikke voldsomt meget og sjældent noget udtalt positivt om denne side af hans forfatterskab.

Dramatiker i almindelig forstand var han nu nok heller ikke, men han kunne skabe både smukke, sælsomme, satiriske og grotesk-bizarre teateroplevelser - især indenfor især den korte dramatiske form. Mest udtalt ser vi dette $i$ hans vaudeviller og poetiske rammehandlinger, som f.eks. komedierne Den ny Barselstue, Fuglen i Paretraet, En Komedie i det grønne og En nat $i$ Roeskilde.

I disse værker samt i enkelte af hans større tragedier og historisk orienterede skuespil forstår han at udnytte hele teatermaskineriet med ægte dramatisk forståelse. Det så teaterhistorikeren Thomas Overskou allerede i forbindelse med Andersens debutarbejde i 1829 komedien Kjarlighed paa Nikolai Taarn, eller Hvad siger Parterret?, hvorom han skrev:

„Phantasie, Lune, Ironie, heldig Anvendelse af charakteristiske Musiknumre og et særdeles godt Blik for theatralsk Effect tydede paa et ualmindeligt Talent for dramatisk Eventyrdigtning."

Andersen var også en eminent oversætter og bearbejder af udenlandske teaterstykker. Han kunne lokalisere et egnet stof, fordanske det med vittige replikker og viser, og tilpasse det til danske forhold. Nogle af disse stykker har vist sig levedygtige helt op til vor egen tid, og vi skal i aften se en prøve på en scene fra et af disse værker, nemlig slutscenen fra en af Andersens mest populære teatertekster, komedien En Nati Roeskilde.

Den udspiller sig en sen nattetime i et værelse på Postgården i Roskilde.
Hr. Graah - som et par år tidligere har fingeret sin egen død ved en drukneulykke for derved at slippe ud af sit ægteskab med den strenge Amalie - lever nu lykkelig og inkognito. Han indkvarterer sig en sen nattetime på et værelse i Roskilde, hvor Hr. Rummel sover højlydt snorkende i værelsets anden seng. De to mænd falder i snak og langsomt bliver det klart for dem begge, at de er gift med én og samme kvinde-Amalie.

For nu at afklare hvem, der egentlig er Amalies lovmæssige ægtemandmed de pligter der deraf følger - beslutter de at lade skæbnen råde i form af et kortspil, hvor vinderen skal være den retmæssige ægtemand - et kortspil de vel at mærke begge ønsker at tabe.

Men pludselig ankommer der et natligt ekspresbrev, som vender totalt op og ned på situationen - og hele komedien.

Komediens slutscene udføres her af skuespillerne Christian Steffensen (som Hr. Rummel), Folmer Rubæk (som Hr. Graah) og Ellen Rasmussen (som En Pige) fra teatertruppen Den Danske Skueplads. De ledsages af pianisten Allan Andersen, fløjtenisten Søren Barfoed og cellisten Bent Fomsgaard.

Andersens umiddelbare evne til at kommunikere med sit publikum fra scenen skyldtes også hans fine musikforståelse. Han kendte som få sin samtids opera- og musikrepertoire og med sikker hånd indlagde han egnet musik til sangnumrene i sine mange vaudeviller, eventyr- og folkekomedier.

Men også som operalibrettist besad han stor musikalsk forståelse og indsigt. Selv udtalte han herom i et brev: "om end jeg ikke kjender Noder, saa har jeg dog Øre". Udstillingen Digterens Teaterdrømme er delt op i en indledende teaterfoyer, hvor vi præsenteres for datidens teater og de mange åndsfæller Andersen efter egne 
udsagn havde blandt fortidens og samtidens dramatikere, komponister og dansere.

Fra foyeren bevæger vi os ad en art teaterkorridor eller bagscene, hvor drengen Hans Christians lange og svære vej til scenen beskrives - en art Via dolorosa - eller smertens vej - frem mod den lykkelige debut som teaterdigter i 1829, hvor anerkendelsen og berømtheden endelig forekom ham at være indenfor rækkevidde.

Dernæst begiver vi os ind på Andersens egen scene. I en nyproduceret DVD-film skildres han liv med de tre kunstarter, skuespillet, operaen og balletten. Dette afsnit er suppleret med originalt materiale, der skildrer fem af hans væsentligste skuespil samt det intense kunstneriske samarbejde han havde med sine to jævnaldrende venner fra den store 1805 generation, komponisten I.P.E. Hartmann og balletmester August Bournonville.

Afsnittet slutter med en kalejdoskopisk fantasi over de mange elementer og ingredienser, der tilsammen udgør Andersens rige og fabulerende teaterunivers.

Som en art"Epilog" skildres i udstillingens sidste afsnit sam- og eftertidens kommentarer til hans teatervirke under overskriften "Teaterdigteren til Debat".

Udstillingen giver med andre ord et indblik med "teaterøjne" i et hidtil noget underbelyst område af digterens livsværk.

Dermed håber Det Kongelige Bibliotek, at bidrage til en bredere forståelse af alsidigheden i H.C. Andersen kreative geni på scenen. Måske vil udstillingen tillige - og det vil så være redaktørens personlige intention og håb - bidrage til at også nutidens teaterverden vil få øje på nogle af de kvaliteter og udfordringer, der stadig ligger i Andersens dramatiske produktion.

I udstillingen vil man opleve, at hvert hovedafsnit er ledsaget af et udvalgt Andersen-citat, der belyser det pågældende afsnit i form af et slags åndeligt ledemotiv fra hans eget fine teatersind.

Andersen var selv på det rene med, at han ofte blev modarbejdet og kritiseret, når han som digter vovede sig ind på teatrets område. Hans samtid mente og udtalte således næsten alt, hvad der kunne siges og tænkes om hans ambitioner som teaterdigter. Selv svarede han igen på denne undertiden bidske - ja næsten hadske kritik ved på sin egen lakoniske måde at nedfælde følgende lille vers i et brev til en nær teaterven:

\section{En fandt mig født for Drama En for Poesi \\ En for Agurker \\ Og en for Potpourri.}

Døm nu selv, når De har set udstillingen om teaterdigteren H.C. Andersen, om han var "til Drama, eller Poesi, til Agurker eller Potpourri". Og fordyb Dem yderligere i stoffet derhjemme, når De fra og med digterens fødselsdag den 2. april vil kunne gense udstillingen i en udvidet web-version i de elektroniske sfærer, nærmere bestemt på Det Kongelige Biblioteks hjemmeside for webudstillinger på adressen $w w w . k b . d k$.

Rigtig god fornøjelse med udstillingen Digterens Teaterdrømme!

Udstillingen Digterens Teaterdrømme - H.C. Andersen og Teatret vises i Den Sorte Diamant indtil 22. oktober 2005. 


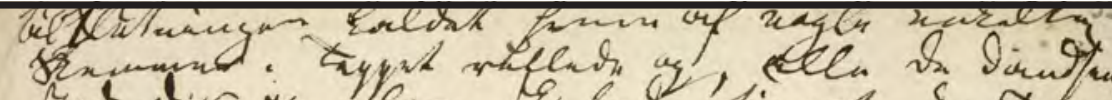

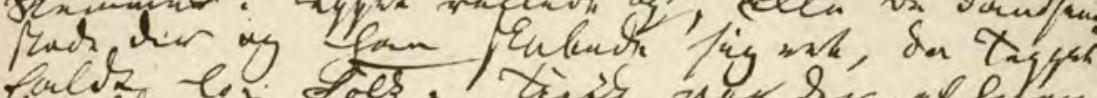

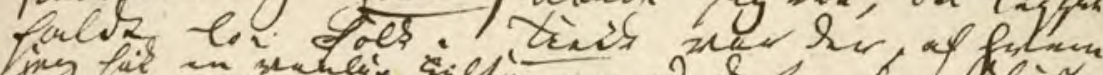

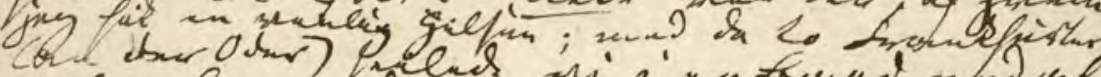

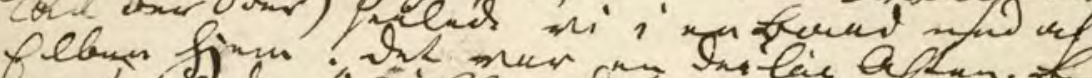

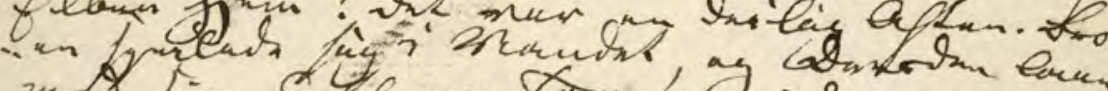

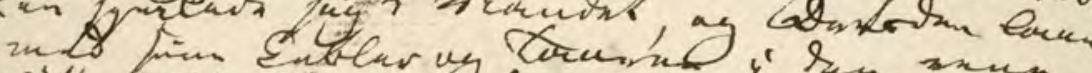

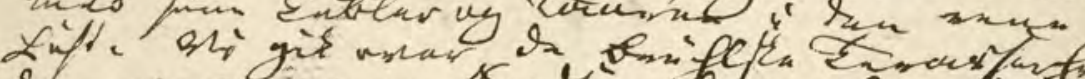

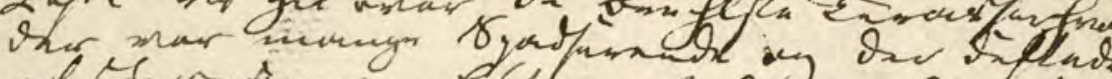

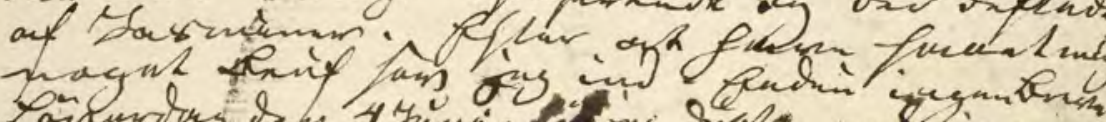

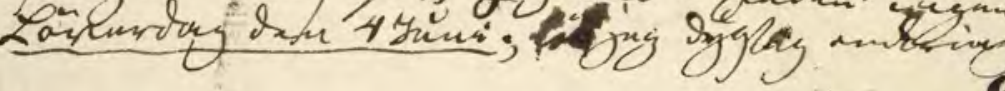

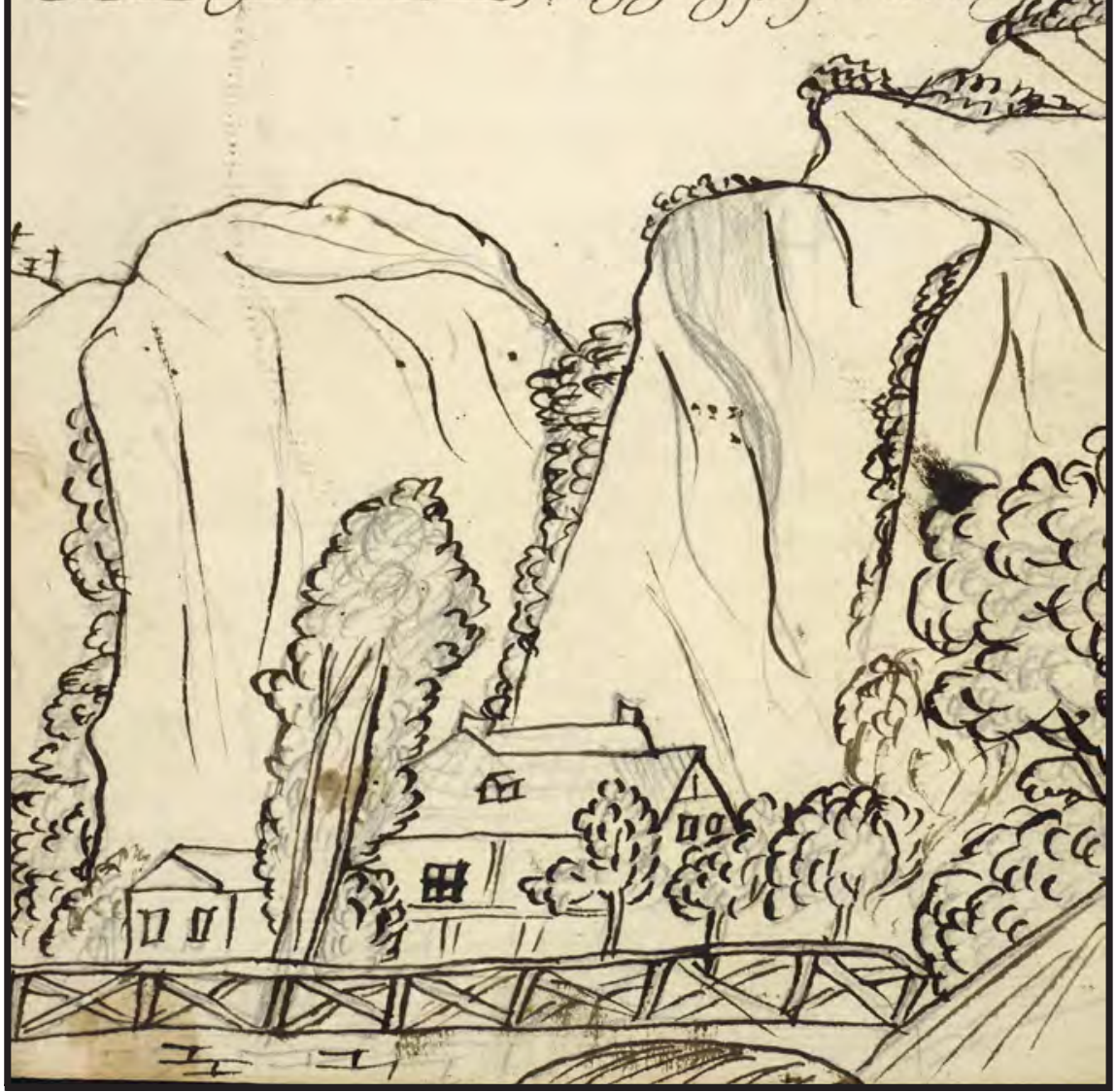

Dagbogsblad fra H.C. Andersens forste rejse til Tyskland 1831. 